\title{
THE CHOISE OF PARAMETERS FOR THE MONITORING AND THE MAINTENANCE OF ARCHITECTURAL STONE SURFACES
}

\author{
E. Zendri a, *, E. Balliana a, F.Caterina Izzo a, M. Melchiorre Di Crescenzo a, L. Falchi a, M. Sgobbi a, G. Biscontin a
}

a Dept. of Environmental Sciences, Informatics and Statistics, Ca' Foscari University of Venice, Via Torino 155/b, 30172 Venice, Italy -

(elizen, eleonora.balliana, fra.izzo, marta.melchiorre, laura.falchi, manuela, bisco)@unive.it

KEY WORDS: monitoring, maintenance, threshold limit values, efficiency, protection, cultural heritage

\begin{abstract}
:
The maintenance of stone buildings aims to preserve artefacts, to reduce the economic management costs and to extend the lifetime of the restoration interventions. Up to now, there are no clear regulations regarding useful parameters which can be used for evaluating the efficiency of surface treatments for the consolidation and protection of stone. The main goal of this work is to identify possible important "chemical-physical parameters" and their threshold limit values. In this context, the determination of the surface water absorption and colour variation may be important tools for the control and the monitoring over time of the state of conservation of the architecture stone surfaces. These parameters are strongly related not only to the surface conservation state but also to products efficiency. Moreover, they can be easily measured at low cost by specifically trained personnel.
\end{abstract}

\section{MONITORING AND ARCHITECTURAL SURFACE: DEFINITION AND MEANING}

To evaluate and monitor the conservation state of an artefact is very complex as many different aspects are involved: the chemical-physical degradation processes of the materials; specific environmental conditions; non-invasive or possibly micro-invasive analysis; etc (Biscontin, 2009).

Recent studies have tried to estimate the risks associated with the interaction between artefacts and the environmental conditions ( Doehene, 2010; Maravelaki, 1992; Bonazza, 2009) in the idea also to give some general guidelines. In general, the environment parameters to be monitored should be selected considering the chemical composition of the support and, as underlined in recent studies, the well known gaseous pollutants responsible of the degradation of most of the artefacts: $\mathrm{CO}_{2}$, $\mathrm{SO}_{2}$ (less indicative as degradation factor respect the past), $\mathrm{O}_{3}$ (especially as indoor value), NOx, etc. (De la Fuente, 2011; Watt, 2009). It is however not easy to define in advance some general and absolute parameters that need to be monitored as often strongly related to the specific characteristics of the artefact, to the local environment conditions and also the use of the buildings. Moreover, the monitoring campaigns should not be limited to the artefact conservation state, but should be extended to the control over time of the effectiveness of the treatments including the control of the temperature (in association with the $\mathrm{RH} \%$ ), the rainfall (e.g. $\mathrm{pH}$ value, direct/indirect action) and moreover to the anthropogenic contribution (that is to say, the visitors).

A complete monitoring campaign might not always be applicable to all the architectonic surfaces due to many factors as: the time necessary for collecting reliable results; the cost of such monitoring campaign; the state of conservation of the artefact itself which sometimes requires urgent interventions, etc. In this frame, the definition of "general models" is very important even at local level and helps monitoring the artefact conservation state and planning when an intervention of restoration-conservation is needed. The selection of the more useful and representative parameters is therefore crucial for an effective monitoring and knowledge of the conservation state.

An emblematic example about the necessity to re-evaluate the contribution of the possible environment degradation parameters is the case of the Ghirlandina Tower in Modena (Italy) (Sandrolini, 2011). In a first step the $\mathrm{SO}_{2}$, commonly indicated as one of the most important degradation factor in urban areas, was selected as the main degradation factor of the tower stone. The monitoring campaign pointed out that the impact of the $\mathrm{SO}_{2}$ level, in relation to the $\mathrm{RH} \%$ values, was very low, while the freeze-thaw cycles was recognized as the main cause of degradation.

Once the conservation state and the causes of degradation of the structure are defined, the attention is usually focused on the practical treatment. This moment often leads to the downfall of the monitoring of the artefact conditions as many people consider the monitoring campaign concluded by the intervention. The treatment indeed defines the "reference zero point" for the monitoring over time of the artefact conservation state (preventive conservation and sustainability of the intervention). In fact, while the monitoring of the artefact conservation state before the intervention defines the threshold alarm beyond which an intervention is needed, the monitoring after the intervention allows to evaluate the effectiveness of the intervention over time, aiming to target the future maintenance interventions and to contain the maintenance costs.

The approach to the importance of the monitoring is therefore an important educational aspect, as outlined also by the Euromed Heritage 4 Project "ELAICH" (Educational Linkage Approach In Cultural Heritage) and more specifically by the issues related to monitoring and maintenance (Biscontin, 2011). 


\section{THE MONITORING AFTER THE INTERVENTION: EVALUATE THE EFFICIENCY OF THE INTERVENTIONS AND PRODUCTS}

For architectural stone surfaces, the restoration intervention is generally concluded with the application of polymer-based products (e.g. consolidant, protective products) with waterrepellent characteristics. The efficiency of these treatments is usually based on the reduction of the water penetration and the increase of the cohesion of the structure. The selection of the products is based on data experimentally obtained on standard materials in accordance with national and international regulations and parameters. Common is also to undergo the treated samples to artificial ageing for estimating the duration over time of the treatments.

According to the current Italian Normative, the efficiency of a protective or a consolidant is evaluated in laboratory before and after the application on specimens based on the following parameters (Normal, 1985):

- Colour variations of the support

- Evaluation of the water capillary absorption coefficient

- Measurements of water absorption by total immersion

- Measurements of water absorption at low pressure

- Evaluation of the contact angle (wettability)

- Evaporation rate of water consumption

- Distribution of the product into the support (by porosimetric

measures)

- Measurements of water vapour permeability

It is common, in particular when working on buildings of no great historic value, to select in advance only the more suitable products and the parameters above mentioned in relation to specific requirement and condition of the support. However, while many studies indicate the possible useful parameters for the selection and evaluation of the products efficiency (Ferreira, 2008; VV.AA., 2011), there are no clear indications about the "associated numeric value" out of which the product can be judged as partially or totally ineffective. Moreover, the product efficiency over time is often related to the methods used for the products application and to the specific environmental conditions (Normal, 1985). These parameters are in fact decided in the laboratory under standardised conditions which hardly correspond to the real conditions where the buildings are located.

\section{PROPOSED CRITERIA FOR THE MONITORING OF THE INTERVENTIONS: THE PROTECTION OF STONE SURFACES}

Considering the difficulties to define general criteria for the selection of the more suitable products, two parameters in particular have been proposed: the permeability to water vapour and the water absorption. The water vapour permeability is in fact associated to the "compatibility" between product and support, while the latter gives an estimation of the ability of the product to reduce the contact between water and support (Ferreira, 2008; Normal, 1993). A high reduction of water vapour permeability usually represents a negative property of the treatment, while a high reduction of water absorption represents a positive characteristic.
Considering the two parameters, it is possible to build an hypothetical diagram of the efficaciousness area for the protective products in terms of water vapour permeability vs water absorption (Figure 1).

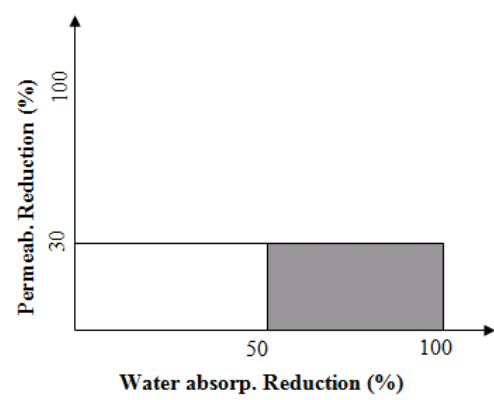

Figure 1: Hypothesis of the efficaciousness area for the protective products in terms of water vapour permeability and water absorption

Based on our previous experiences, the limit value for a good protection of the substrate will be equal to $50 \%$ for the water absorption by capillarity and $20 \%$ for the reduction in water vapour permeability taking into account also the compatibility between the systems product-stone.

There are some limitations in the choice of the permeability as indicative parameter of the efficiency of the treatment, because linked to the environmental conditions ( $\mathrm{RH} \%$ in particular) that is a difficult parameter to estimate outdoor. It means that the permeability, even if representative of the "compatibility" between support, consolidant-protective product and environment, cannot be selected as the only parameter for evaluating the efficiency of the treatment.

In this context, it becomes clear how important is to define significant parameters for evaluating the real efficiency of the interventions (Tsakalof, 2007). Moreover the monitoring of these parameters will give us an idea of the quality of the products over time. Figure 2 shows the most significant parameters and their relative importance ("weight") for evaluating the application of a protective coating on stones exposed to the external environment.

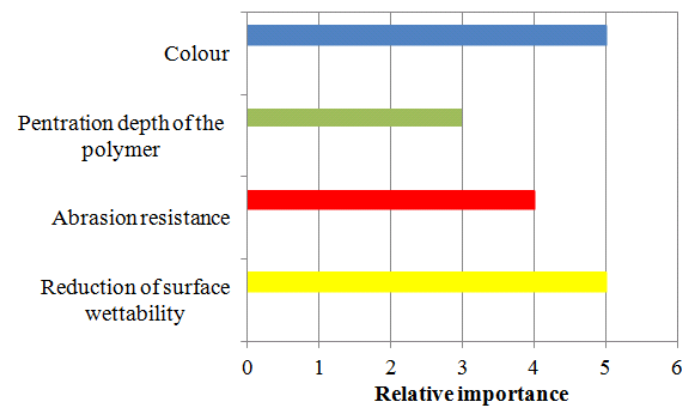

Figure 2: Most significant parameters and their relative importance ("weight") for an intervention of protection of stone exposed to the external environment

Based on Figure 2, the most important parameters for the selection and the monitoring of a protective intervention are: the surface final aspect (as chromatic change), the reduction of the material wettability and the surface abrasion resistance. The 


\section{ARCHITECTURAL STONE SURFACES}

abrasion resistance is however playing a minor role. Its value is mainly linked to the mechanical action of rain and wind, but in times relatively long enough to be considered not relevant. The penetration of the polymer in the material has a high relevance in the case of consolidation, while it is less important in the case of the protection efficiency as the polymer penetration is limited mainly to the surface.

Nowadays, the colour variations of the materials before and after the product application are monitored at defined time intervals with portable spectrophotometers easy to use and able to provide tristimulus parameters (L*a*b*) (Nicoletti, 2001). Surface colour variations are commonly expressed in term of $\Delta \mathrm{E}$ and values below 3 are accepted as not appreciated by the human eye. Whenever this value is higher an intervention should be planned aiming to the elimination of the altered protective, when possible, and its replacement with a more a more stable and less invasive product.

The reduction of the water absorption by the stone surface after product application is generally estimated as a variation in term of absorption of water at low pressure (Biscontin, 1984). The system is of low cost, easy to use and can be done also in loco directly on the building. Alternative methods (e.g. use of sponges soaked in water) have been also proposed during the years but there are still doubts about the reliability of these methods and of the obtained results (Tiano, 2006).

As in the case of the colour variation, the success of the protective treatment must always be referred to the untreated material in term of decrease of water absorption coefficient. Moreover, the value of the untreated material would give the threshold limit below which the product can be considered ineffective and needs to be replaced. However, as this difference is strictly linked to the chemical-physical nature of the materials and the application time, it is necessary (as for the colour variation) to give an indicative standard procedure useful for evaluating when the product protection is compromised.

The quality of the product water protection could be expressed as a difference in percentage between the value at $\mathrm{t}_{0}$ (measured just after the product application) and the value measurement after a fix time period. Whenever this value is higher than $50 \%$ the protection is compromised and the product must therefore be removed and replaced (Figure 3).

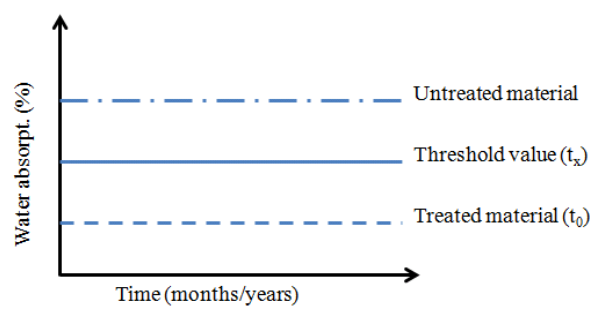

Figure 3: Threshold limits below which the product can be considered ineffective in terms of water absorption

The two proposed value for the colour variation and the water absorption might therefore be considered as threshold values for estimating the tangible protective efficiency of an intervention on stone surface.

The monitoring over time of the quality of the restoration is one of the most unclear topics. This operation is really important and must be designed case by case, as strictly connected to the chemical-physical characteristics of the support, the conditions of conservation, the use of the building (museum, church, etc.), the environmental conditions, etc. While there is a common agreement on the importance of the monitoring of the treatments over time, there are no existing guidelines on how this operation can be performed, which parameters can be used and more important how often. Recent publications (Vandevoordle, 2009) have shown that simple semi-annual inspections of selected areas can help in evaluating the efficiency of the protective coatings over time. The collected data give not only an estimation of the efficiency of the product but also a model of the possible product deterioration over time. In particular, variations of the surface colour changes and wettability offer some of the most interesting results because connected to the specific product requirements. Moreover, these parameters can easily be interpreted and measured at low cost, leading to the concepts of maintenance and sustainability.

A specific case study is the restoration of the Girlandina Tower (Modena, Italy) (Cadignani, 2012). Thanks to a maintenance and prevention project, the conditions of the materials and of the environment were monitored just after the interventions and over time for checking the effectiveness of the interventions. The collected data gave the possibility to evaluate, in real cases, the importance of the parameters selected for monitoring the conservation state of the surfaces and moreover their possible threshold values. In the case of the Girlandina Tower, the effectiveness of the protection treatment of the stone was evaluated based on the color variations $(\Delta \mathrm{E})$ and the water absorption by low-pressure (pipette method).

Figure 4 shows the variation in colour, as $\Delta \mathrm{E}$ values, measured at different time over a balustrade in red Verona marble treated with an acrylic nano-emulsion. After 26 months from the treatment, the colour variations, as $\Delta \mathrm{E}$, are still very small and below the perception value $(\Delta \mathrm{E}=3)$.

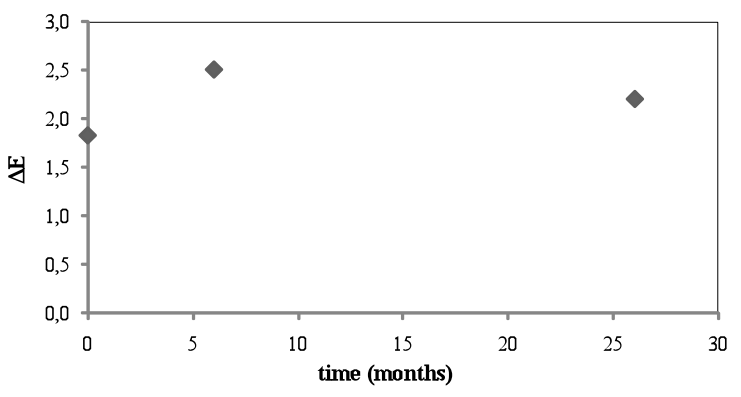

Figure 4: AE values versus time (months) of treated red Verona marble (Girlandina Tower, Modena)

After six months, the value of the water absorption at low pressure (Figure 5) indicates a modest reduction of the efficiency of the water-repellent product, compared to the value just after application. Regular monitoring of this parameter will allow specific intervention in the areas where this reduction is most significant, as those most prone to rain degradation. 


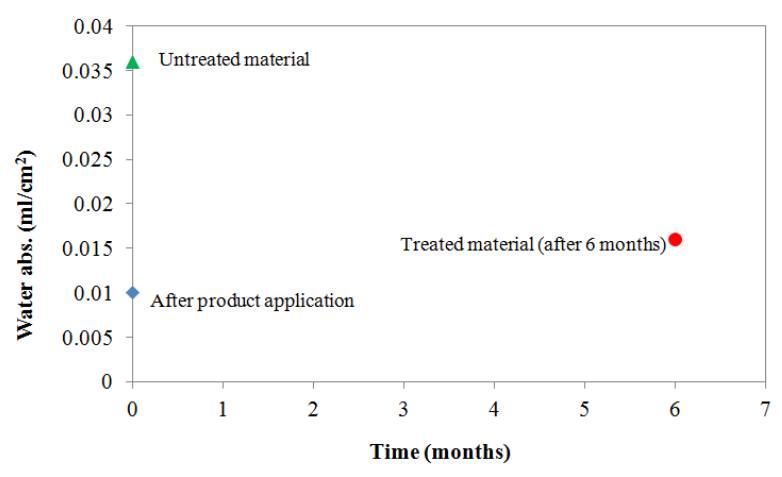

Figure 5: water absorption (as $\mathrm{ml} / \mathrm{cm}^{2}$ ) under low pressure methodology by the stone as untreated, just after application and after 6 months of product application

\section{CONCLUDING REMARKS}

The monitoring of architectural surfaces is complex and cannot be reduce to the simple monitoring of the conservation state (e.g. deposition of dust, formation of fissures, etc.). A complete monitoring intervention must include the control over time of the effectiveness of the interventions and of the products. This must lead to a possible maintenance plan aiming to a preventive conservation and to the reduction of the economic costs and, most important, cultural losses.

The obvious difficulty of establishing standard criteria for evaluating the effectiveness of conservative treatments can partly be overcome by defining specific parameters that need to be considered in relation to the expected product performances. In the case of the protection, a reduction of the surface water absorption (wettability) must be achieved without changing its final appearance (colour). The reduction of water absorption and the colour of the surface are parameters easy to measure and to monitor directly on the site even from not expertises. Combining the data collected in situ and in the laboratory, it will be possible to suggest threshold values for which the treatment can be considered effective. It is here proposed to set these thresholds values to variations equal to $3 \% \Delta \mathrm{E}$ for the surface colour variations and to $50 \%$ for the reduction of water adsorption, compared to the values obtained just after application of the protective. The semi-annual or annual monitoring of these parameters will give an estimation of the effective quality of the treatments over time and will give the possibility to intervene before the stone material is compromised.

\section{REFERENCES}

Biscontin, G. (et al.), 1984. Color changes in resin treated materials, P.L. Parrini (Ed.): Proceeding of the International Congress on Scientific Methodologies Applied to Works of Art 1984, Milan, pp. 100-103.

Biscontin, G., 2009. The Ghirladina Tower. Conservation Project. Sossella L. (Ed.), The Girlandina tower. History and restoration, Rome, Book, pp. 237-241.
Biscontin, G., 2011. ELAICH - Educational Linkage Approach in Cultural Heritage Module 5 "Monitoring and Maintenance" http://www.elaich.technion.ac.il/e-learning/en/modules/module5.html

Bonazza, A. (et al.), 2009. Mapping the impact of climate change on surface recession of carbonate buildings in Europe. Sci Total Environ, 407(6), pp. 2039-2050.

Cadignani, R. (et al.), 2012. Il restauro della Ghirlandina: analisi preliminari, monitoraggio degli interventi $e$ prevenzione, Arcadia Ricerche (Ed.): Scienza e Beni Culturali 2012 Full Papers Procedeeing, Vol. XXVIII, Venice 2012, pp.181-191.

De la Fuente, D. (et al.), 2011. City scale assessment model for air pollution affects on the cultural heritage. Atmos Environ, 45(6), pp. 1242-1250.

Doehne, E. (et al.), 2010. Stone Conservation. An Overview of Current Research. The Getty Conservation Institute (Ed.), Los Angeles, Book.

Driussi, G. (et al.), 2010. Maintenance of the external stonewalls for the Ghirlandina Tower. Sossella L. (Ed.), The Girlandina tower. History and restoration, Rome, Book, pp. 295-301.

Ferreira Pinto, A. P. (et al.), 2008. Stone consolidation: the role of treatment procedure. J Cult Hert, 9(1), pp.38-53.

Maravelaki, P. (et al.), 1992. Evaluation of Deterioration Processes on the Istria Stone of Venetian Monuments, J. Delgado Rodrigues, F. Henriques, F. T. Jeremias (Eds.): Proceedings of the 7th International Congress on Deterioration and Conservation of Stone, Laboratório Nacional de Engenharia Civil, Lisbon 1992, pp. 163-173.

Nicoletti, R. (et al.), 2001. Pavimentazioni in cotto del Palazzo Reale di Torino: applicazioni sperimentali per la conservazione, Arcadia Ricerche (Ed.): Scienza e Beni Culturali 2001 Full Papers Procedeeing, Vol. XXII, Venice 2001, pp.1105-1113.

Normal 20/85, 1985. Interventi Conservativi: Progettazione Esecuzione e Valutazione Preventiva, CNR-ICR, Roma, Italy.

Normal 44/93, 1993. Assorbimento d'Acqua a Bassa Pressione, CNR-ICR, Roma, Italy.

Tiano P. (et al.), 2006, Biomediated reinforcement of weathered calcareous stones. J Cult Herit, 7(1), pp. 49-55.

Sandrolini, F. (et al.), 2011. The contribution of urban-scale environmental monitoring to materials diagnostics: A study on the Cathedral of Modena (Italy). J Cult Herit, 12(4), pp. 441450 .

Tsakalof, A. (et al.), 2007. Assessment of synthetic polymeric coatings for the protection and preservation of stone monuments. J Cult Herit, 8(1), pp. 69-72.

Vandevoorde, D. (et al.), 2009. Contact sponge method: performance of a promising tool for measuring the initial water absorption. J Cult Herit, 10(1), pp.41-47. 

ARCHITECTURAL STONE SURFACES

VV. AA., 2011. Governare l'Innovazione: processi, strutture, materiali e tecnologie tra passato e futuro, Arcadia Ricerche (Ed.): Scienza e Beni Culturali 2011 Full Papers Procedeeing, Vol. XXVII, Venice.

Watt, J. (et al.), 2009. The effect of air pollution on Cultural Heritage. Watt J., Tidblad J., Kucera V., Hamilton R. (Eds.), Springer, Heidelberg, Book.

\section{ACKNOWLEDGEMENTS}

The authors acknowledge the Architect Rossella Cardignani of the municipality of Modena for the collaboration. 
